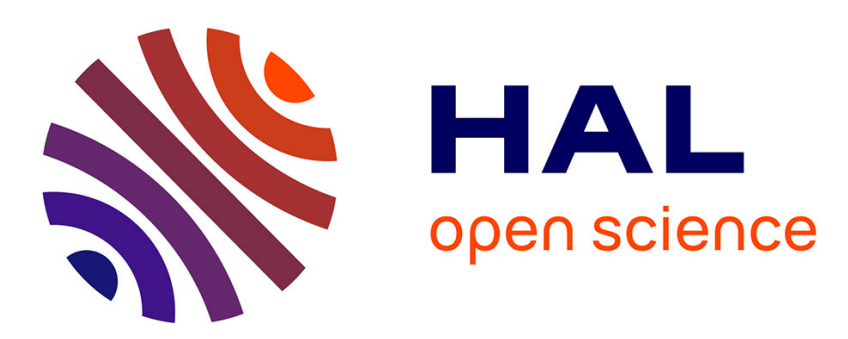

\title{
Interaction of metastable helium atoms with a Mo [110] surface. Secondary electron spectroscopy
}

\author{
C. Boiziau, C. Garot, R. Nuvolone, J. Roussel
}

\section{To cite this version:}

C. Boiziau, C. Garot, R. Nuvolone, J. Roussel. Interaction of metastable helium atoms with a Mo [110] surface. Secondary electron spectroscopy. Journal de Physique Lettres, 1978, 39 (19), pp.339-341. 10.1051/jphyslet:019780039019033900 . jpa-00231512

\section{HAL Id: jpa-00231512 https://hal.science/jpa-00231512}

Submitted on 1 Jan 1978

HAL is a multi-disciplinary open access archive for the deposit and dissemination of scientific research documents, whether they are published or not. The documents may come from teaching and research institutions in France or abroad, or from public or private research centers.
L'archive ouverte pluridisciplinaire HAL, est destinée au dépôt et à la diffusion de documents scientifiques de niveau recherche, publiés ou non, émanant des établissements d'enseignement et de recherche français ou étrangers, des laboratoires publics ou privés. 


\title{
INTERACTION OF METASTABLE HELIUM ATOMS WITH A Mo [110] SURFACE. SECONDARY ELECTRON SPECTROSCOPY
}

\author{
C. BOIZIAU, C. GAROT (*), R. NUVOLONE and J. ROUSSEL \\ Service de Physique Atomique, Centre d'Etudes Nucléaires de Saclay, \\ B.P. $n^{\circ} 2,91190$ Gif sur Yvette, France
}

(Reçu le 9 juin 1978, révisé le 17 juillet 1978, accepté le 24 août 1978)

\begin{abstract}
Résumé. - Des résultats expérimentaux sont présentés concernant l'interaction d'atomes métastables d'hélium et de photons U.V. produits dans une même source, avec une surface de molybdène [110] propre. Grâce à un système de temps de vol, les spectres en énergie des électrons secondaires dûs aux atomes métastables et aux photons peuvent être séparés et enregistrés simultanément. Le traitement mathématique des courbes expérimentales et la comparaison des résultats avec des densités d'état calculées montrent que le processus de désexcitation des $\mathrm{He}^{*}$ est une ionisation résonnante suivie d'une neutralisation Auger.
\end{abstract}

\begin{abstract}
Experimental results are given concerning the interaction of metastable helium atoms and U.V. photons, produced in the same source, with a clean molybdenum [110] surface. By means of a time of flight system the energy spectra of the secondary electrons due to metastable atoms and photons may be separated and recorded simultaneously. Mathematical processing of the experimental curves and comparison of the results with calculated state densities show that the $\mathrm{He}^{*}$ deexcitation process is a resonant ionization followed by an Auger neutralization.
\end{abstract}

In 1954 H. D. Hagstrum [1] announced a means of studying the electronic properties of solid surfaces by their interaction with metastable rare gas atoms, and further work along these lines has since confirmed the interest of this research [2-6].

The results given here show that in the same way as I.N.S. [7, 8] this experimental technique can supply data complementary to those obtained by U.P.S.

Experimental method. - With the experimental set-up used here, already described elsewhere [9], it is possible by a time of flight method to separate the secondary particles due to photons and metastable atoms and record the corresponding signals simultaneously [10]. The source of photons and metastable atoms was designed to give a beam containing no helium atoms of high kinetic energy [11]. The secondary electron energies are analysed by a cylindrical electrostatic analyser [12] which, connected to an electron gun, is also used to characterize the surface by A.E.S.

$\left(^{*}\right)$ Present address : Cie Internationale de Services en Informatique, 35, boulevard Brune, 75680 Paris Cedex 14.
The target having been cleaned in the usual way (ion bombardment with argon and electron bombardment heating), the secondary electron energy spectra are recorded simultaneously, hence under strictly identical experimental conditions : background pressure $\left(<10^{-8} \mathrm{~Pa}\right)$, interval between thermal flash and start of measurement $(\sim 20 \mathrm{~s})$, measurement time (12 $\mathrm{min}$.$) ; the results given were obtained for a$ 45 degree angle of incidence and an angle of observation perpendicular to the target.

Mathematical processing method. - Until recently when P. D. Johnson and T. A. Delchar [13] found that the energy spectrum of electrons produced by interaction of a beam from a non-pulsed source with a nickel surface had to be interpreted as the result of a one-electron mechanism (direct Auger deexcitation), all comparison of experimental results with the theoretical model led to the assumption of a two-electron mechanism (resonant ionization followed by an Auger neutralization) for these interactions, at least for solids with a work function higher than the ionization potential of the metastable atom in question. 
Moreover the validity of this hypothesis was confirmed experimentally by the observation of $\mathrm{He}^{+}$ ions formed near the surface by ionization of the $\mathrm{He}^{*}$ atoms [14]. We therefore have to find a digital computing method capable of deconvoluting the metaelectron energy spectra, for comparison with the photoelectron spectra and the calculated electron state densities. This method, described in another article $[15,16]$, is based on a property of spline functions : the self-convolution product of a spline function of order $q$ is a spline function of order $2 q$, with uniqueness of solution, and uses Marquardt's algorithm for the digital calculation [17].

Conversely it can be useful to self-convolute the photoelectron spectrum and to compare it with that of the metaelectrons.

For this we need only calculate :

$$
M(x)=\int_{0}^{x} F(x-y) \cdot F(y) \cdot \mathrm{d} y,
$$

to obtain point by point the self-convolution product of the function $F(y)$.

Results-discussion. - The photoelectron and metaelectron spectra may thus be obtained experimentally at the same time and compared either directly or after mathematical treatment.
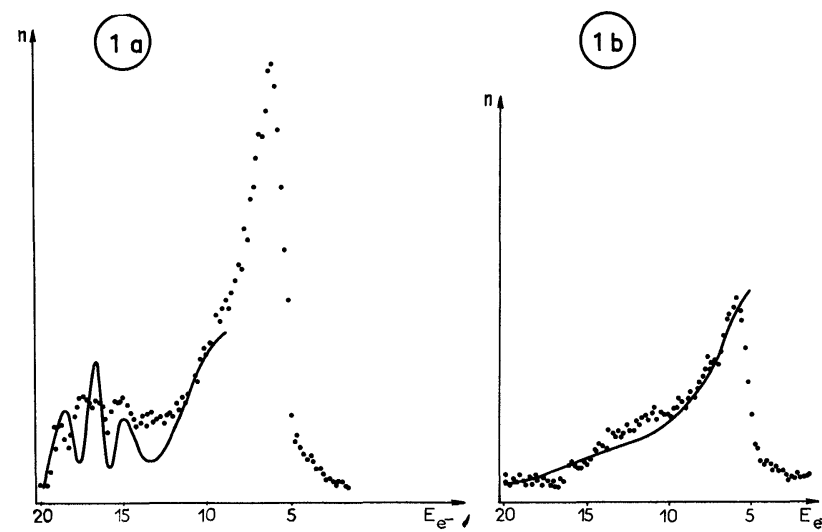

FIG. 1. $-1 a:$ Photoelectron spectrum. $1 b:$ Metaelectron spectrum. Dotted lines : experimental data. Solid lines : $1 a:$ deconvoluted curve of the metaelectron spectrum. $1 b:$ self-convoluted curve of the photoelectron spectrum.

Figure 1 shows the results obtained :

- Our metaelectron spectrum differs from that obtained by Hagstrum with I.N.S. [18]. But, his target was polycrystalline molybdenum. It should be also observed that our spectrum has been carried out with angle resolved electron analysis, whilst Hagstrum's spectrum is achieved with a R.P.D. method on the total current.

- The two experimental curves are different.

- On the other hand the self-convolution product of the photoelectron spectrum practically coincides with the experimental metaelectron curve.

- It is also found that deconvolution of the metaelectron spectrum reveals the same structures as those obtained by photo-emission, but are more pronounced.

Figure $2 a$ shows the comparison of our results with a density of states calculated by I. Petroff and G. R. Viswanathan [19]. Figure $2 b$ shows the same comparison but with a local density of states calculated by Spanjaard [20] for Mo [110].
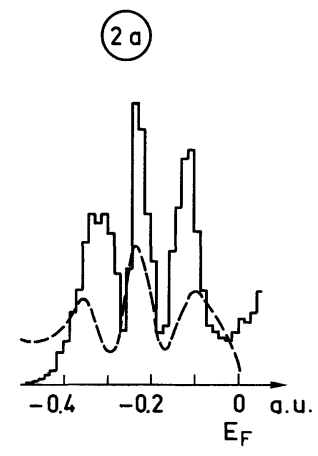

(2b)

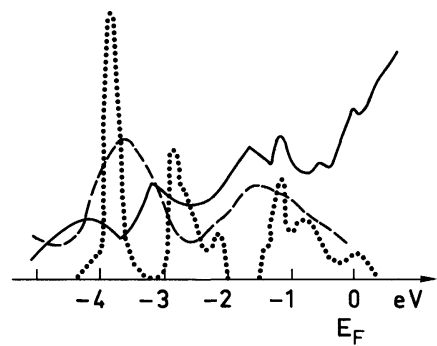

FIG. 2. $-2 a$ : Comparison of the calculated state density [15] (solid line) with the curve obtained by deconvolution of the metaemission spectrum (dashed line). $2 b$ : Comparison of the calculated state density [16] (solid line : extended D.O.S., dotted line : surface states) with the curve obtained by deconvolution of the meta-emission spectrum (dashed line).

In both cases the position of the peaks correspond well.

Thus calling $D(x)$ the density of the initial states in the solid we may consider, according to Hagstrum, that the probability of the elementary process leading to neutralization of the hole corresponding to the $\mathrm{He}^{+}$ion ground level and to expulsion of an electron from the solid, transition probability excluded, is :

$$
D(x-\partial) \cdot D(x+\partial) \text {. }
$$

Since we have an infinity of paired levels $x-\partial$ and $x+\partial$ symmetrical with respect to the level $x$, liable to cause ejection of an electron of given energy, the total probability is thus :

$$
M(x)=\int_{-x}^{+x} D(x-\partial) \cdot D(x+\partial) \cdot \mathrm{d} \partial
$$

This expression, the self-convolution product of the initial state density, is similar to within a scale factor to the mathematical model used to process the experimental curve.

This comparison between theoretical model, experimental results and state density calculations is satisfactory enough to confirm the validity of the theoretical model and the ability of metastable helium on molybdenum to give accurate information on the density of states near the surface of the metal. 


\section{References}

[1] Hagstrum, H. D., Phys. Rev. 96 (1954) 336.

[2] Delchar, T. A., Mac Lennan, D. A., Landers, A. M., J. Chem. Phys. 50 (1969) 1779.

[3] Dunning, F. B., Smith, A. C., Stebings, R. F., J. Phys. B 4 (1971) 1683.

[4] Allison, W., Dunning, F. B., Smith, A. C. H., J. Phys. B 5 (1972) 1175.

[5] Mac Lennan, D. A., Delchar, T. A., J. Chem. Phys. 50 (1969) 1772.

[6] Boiziau, C., Dose, V., Roussel, J., Surf. Sci. 61 (1976) 412.

[7] Hagstrum, H. D., J. Vac. Sci. Technol. 12 (1975) 7.

[8] Sickafus, E. N., Phys. Rev. B 7 (1973) 5100.

[9] Boiziau, C., Nouvolone, R., Roussel, J., soumis à Revue Phys. Appl.

[10] Le Grand, J. J., Schmouchkovitch, A., Autom. Inform. Ind. 54 (1977) 17.
[11] Roussel, J., Boiziau, C., Cong. Nat. Phys. Plasmas Paris 6-10 déc. 1976.

[12] Ballu, Y., J. Micros. Spectrosc. Electr. 2 (1977) 231.

[13] Johnson, P. D., Delchar, T. A., J. Phys. E. Sci. Instrum. 10 (1977) 428.

[14] Roussel, J., Boiziau, C., J. Physique 38 (1977) 757.

[15] Garot, C., Bolziau, C., soumis à J. Computational Physics.

[16] Garot, C., Thesis. Université Paris-Sud (Orsay) juin 1978.

[17] Marquardt, D. W., S.I.A.M. J. Appl. Math. 11 (1963) 431

[18] Hagstrum, H. D., Phys. Rev. 104 (1956) 672.

[19] Petroff, I., Viswanathan, C. R., Phys. Rev. B 4 (1971) 799.

[20] Noguera, C., Spanjaard, D., Jepsen, D. W., Phys. Rev. B 17 (1978) 607. 